\title{
Kinetic Study on the Radical Polymerization of Sodium I soprenesulfonate in Water
}

\author{
Yusuke TsudA, Taisuke ItOnAGA, Keiichi Bessyo, ${ }^{*}$ and Hisao ONO* \\ Department of Biochemistry \& Applied Chemistry, Kurume National College \\ of Technology, 1-1-1 Komorino, Kurume, Fukuoka 830-8555, Japan \\ ${ }^{*}$ Tsukuba Research Laboratories, JSR Corporation, \\ 25 Miyukigaoka, Tsukuba, Ibaraki 305-0841, Japan
}

(Received February 20, 2001; Accepted May 22, 2001)

\begin{abstract}
KEY WORDS Water-Soluble Polymer / Sodium Isoprenesulfonate / Kinetic Study / Activation Energy /
\end{abstract}

Water-soluble polymers are important in a wide variety of industrial applications including mineral and petroleum recovery, fluid modification, controlled drug release, personal care formulations, industrial water treatment, and wastewater treatment. ${ }^{1}$ There are several important sulfonate-containing water-soluble polymers, such as poly(vinylsulfonic acid) (PVSA) and its salts, and poly ( $p$-styrenesulfonic acid) (PSSA) and its salt. ${ }^{2}$ Extensive development has been also conducted on acrylic sulfonate-containing monomers, such as 2-sulfoethylmethacrylate (SEM) and 2-acrylamido2-methylpropanesulfonate (AMS). ${ }^{2}$

Recently, JSR Corporation has developed a novel sulfonate-containing diene monomer, sodium isoprenesulfonate (IPS) synthesized from isoprene and sulfur trioxide (Figure 1). ${ }^{3,4}$ This new class of water-soluble monomers has excellent polymerization ability and corresponding water-soluble polymers have been proven useful for a variety industrial applications, e.g., as an anionic surfactant for coal water slurry. ${ }^{5,6}$ Ono et al. have investigated the polymerization of IPS initiated by potassium persulfate (KPS) in water and concluded that 1,4-polymerization and 3,4-polymerization proceed at approximately the same ratio, and that weight-average molecular weights of polymers range from $2.9 \times 10^{4}$ to $11.2 \times 10^{4} \mathrm{~g} \mathrm{~mol}^{-1}$ according to the GPC measurement using sodium polystyrene sulfonate standards (Figure 2). ${ }^{4}$ This paper describes the kinetic results of radical polymerization of IPS in water, such as rate of polymerization $\left(R_{\mathrm{p}}\right)$ and activation energy of polymerization $\left(E_{\mathrm{a}}\right)$, where sodium persulfate (SPS) was used as initiator.

\section{EXPERIMENTAL}

\section{Materials}

IPS was supplied as water solution (41.6 wt\%) by JSR Corporation. SPS was purchased from Wako Pure Chemical Industries, Ltd. and used as received. Ionfree water was used.

\section{Typical Procedure of Polymerization}

$98.75 \mathrm{~g}$ of $25.3 \mathrm{wt} \%$ IPS in water was added to a $300 \mathrm{~mL}$ three-necked reaction flask with a mechanical stirrer under nitrogen flow, and then heated by hotwater bath. $1.25 \mathrm{~g}$ of $20 \mathrm{wt} \%$ SPS in water was added at $40^{\circ} \mathrm{C}$. Eventually, monomer concentration was $25 \mathrm{wt} \%$ $\left(1.67 \mathrm{~mol} \mathrm{~L}^{-1}\right)$. A small amount of the reaction mixture was withdrawn from the reaction mixture every $10 \mathrm{~min}$ up to $1 \mathrm{~h}$, and every 30-60 min from $1 \mathrm{~h}$ up to $4 \mathrm{~h}$. These<smiles>C=CC=CCOS(=O)(=O)OCCO</smiles><smiles>CC1=CCOS(=O)(=O)C1</smiles>

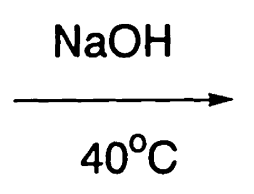<smiles>C/C=C\C=C\S(=O)(=O)O[Na]</smiles>

\section{(E)-Sodiumlsoprenesulfonate (IPS)}

Figure 1. Synthesis of Sodium Isoprenesulfonate (IPS). 
<smiles>C=CC(C)=CS(=O)(=O)O[Na]</smiles>

(E)-Sodium Isoprenesulfonate (IPS)<smiles>C/C(=C/CCC(C)(C)C)C(C)C</smiles>

and<smiles>CC(C)=CCC(C)=CCC(C)(C)C</smiles>

trans-<smiles>C/C(=C/C(CC(C)(C)C)C(C)(C)C)C(C)(C)C</smiles>

3,4-Poly(IPS)

\section{1,4-Poly(IPS)}

Figure 2. Radical polymerization of Sodium Isoprenesulfonate in Water.

samples were weighted and immediately diluted with water in $250 \mathrm{~mL}$ volumetric flask to a concentration of $20-40 \mathrm{~m} \mathrm{~L} \mathrm{~L}^{-1}$ and analyzed by UV spectrophotometry.

\section{Techniques}

UV spectra were recorded on a Hitachi U-3300 UV spectrophotometer. Conversions of monomer to homopolymer were determined as decrease of the conjugated diene peak of IPS monomer $(235 \mathrm{~nm}) v s$. a calibration curve prepared using seven IPS water solutions with different concentrations.

\section{RESULTS AND DISCUSSION}

IPS was polymerized in water at various concentration and temperatures using SPS as an initiator (Figure 2). At this point, it is appropriate to briefly discuss the experimental procedure used to determine conversion and $R_{\mathrm{p}}$. One of the most practical methods to measure the conversion from monomers to polymers is the gravimetric method, that is, isolating the polymer from the reaction mixture by either precipitation of the polymer by addition of a non-solvent or by distillation of monomer. ${ }^{7}$ However, these methods present difficulties, since both IPS and the corresponding homopolymers show similar solubility and are solids. Conversions can also be experimentally followed by measuring change in any property that differ for the monomer and polymer, such as density, refractive index, or the spectral absorption. ${ }^{7}$ It has been noticed that IPS in water has a strong adsorption at $235 \mathrm{~nm}$ in the UV spectrum, while the corresponding homopolymers, where unreacted IPS was removed by dialysis, do not absorb at $230 \mathrm{~nm}$ or above. Thus, conversions were easily and accurately determined by decrease in the conjugated diene peak of IPS.

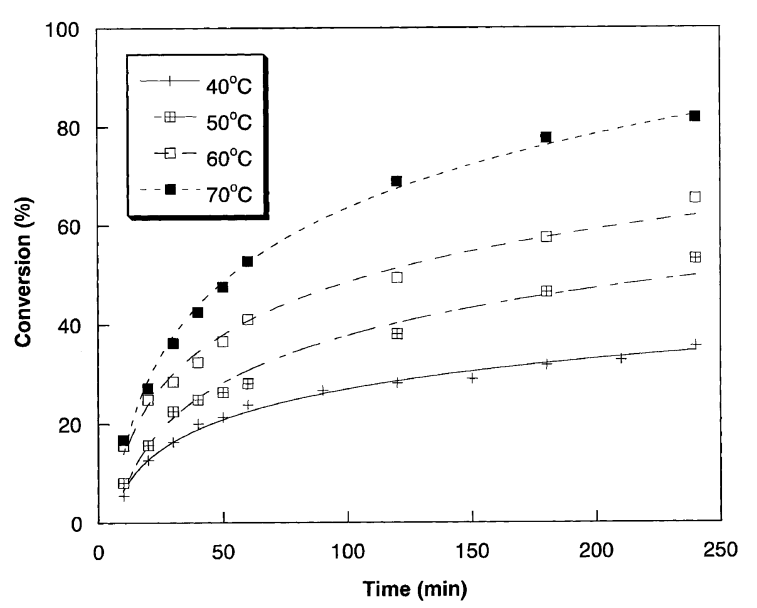

Figure 3. Time-conversion curves in the polymerization of IPS with SPS in water at different temperatures $\left([\mathrm{IPS}]=1.67 \mathrm{~mol} \mathrm{~L}^{-1}\right.$, $[\mathrm{SPS}]=1.13 \times 10^{-2} \mathrm{~mol} \mathrm{~L}^{-1}$ ).

Figure 3 shows time-conversion plots observed at $40,50,60$, and $70^{\circ} \mathrm{C}$ at initial concentrations of IPS and SPS of $25.0 \mathrm{wt} \%\left(1.67 \mathrm{~mol} \mathrm{~L}^{-1}\right)$ and $1.00 \mathrm{wt} \%$ $\left(1.13 \times 10^{-2} \mathrm{~mol} \mathrm{~L}^{-1}\right)$ respectively. Higher conversions were reached as polymerization time and/or temperature increased. The highest conversion reached $82 \%$ at $70^{\circ} \mathrm{C}$ after $4 \mathrm{~h}$. $R_{\mathrm{p}}$ was determined from the initial slope of steep rise of conversion curves and is summarized in Table I. As the weight \% (wt\%) unit is generally used in the chemical industry, all reactants were weighed by $w t \%$, and calculation was carried out using molar units. From the Arrhenius plots shown in Figure 4, overall $E_{\text {a }}$ of polymerization was calculated to $25.6 \mathrm{~kJ} \mathrm{~mol}^{-1}$. This is higher than the reported values for the polymerization of acrylonitrile in water $\left(17.2 \mathrm{~kJ} \mathrm{~mol}^{-1}\right)$ and methacrylamide in water $(15.5 \mathrm{~kJ}$ $\left.\mathrm{mol}^{-1}\right),{ }^{8}$ and lower than the value for the polymerization of sodium $\mathrm{p}$-styrenesulfonate in water initiated potassium persulfate $\left(46.1 \mathrm{~kJ} \mathrm{~mol}^{-1}\right){ }^{9}$ The temperature dependence of $R_{\mathrm{p}}$ of IPS may be lower than that of 
Table I. Rate of polymerization $\left(R_{\mathrm{p}}\right)$ of $\mathrm{IPS}^{\mathrm{a}}$ with $\mathrm{SPS}^{\mathrm{b}}$ in water at various conditions

\begin{tabular}{|c|c|c|c|}
\hline$\frac{\text { Temp }}{{ }^{\circ} \mathrm{C}}$ & $\frac{[\mathrm{IPS}]}{\mathrm{wt} \%\left(\mathrm{~mol} \mathrm{~L}^{-1}\right)^{\mathrm{c}}}$ & $\frac{[\mathrm{SPS}]}{\mathrm{wt} \%\left(10^{-2} \mathrm{~mol} \mathrm{~L}^{-1}\right)^{\mathrm{c}}}$ & $\frac{10^{4} R_{\mathrm{p}}}{\mathrm{mol} \mathrm{L} \mathrm{L}^{-1} \mathrm{~s}}$ \\
\hline 40 & $25.0(1.67)$ & $1.00(1.13)$ & 1.74 \\
\hline 50 & $25.0(1.67)$ & $1.00(1.13)$ & 1.98 \\
\hline 60 & $25.0(1.67)$ & $1.00(1.13)$ & 3.07 \\
\hline 70 & $25.0(1.67)$ & $1.00(1.13)$ & 3.92 \\
\hline 50 & $6.25(0.40)$ & $1.00(1.13)$ & 0.28 \\
\hline 50 & $12.5(0.81)$ & $1.00(1.13)$ & 0.75 \\
\hline 50 & $25.0(1.67)$ & $1.00(1.13)$ & 1.98 \\
\hline 50 & $40.0(2.79)$ & $1.00(1.13)$ & 5.22 \\
\hline 50 & $25.0(1.67)$ & $0.25(0.28)$ & 1.19 \\
\hline 50 & $25.0(1.67)$ & $0.50(0.56)$ & 1.52 \\
\hline 50 & $25.0(1.67)$ & $1.00(1.13)$ & 1.98 \\
\hline 50 & $25.0(1.67)$ & $2.00(2.29)$ & 3.31 \\
\hline
\end{tabular}
trations are practically based on $\mathrm{wt} \%$, then converted to $\mathrm{mol} \mathrm{L}^{-1}$ for calculation.

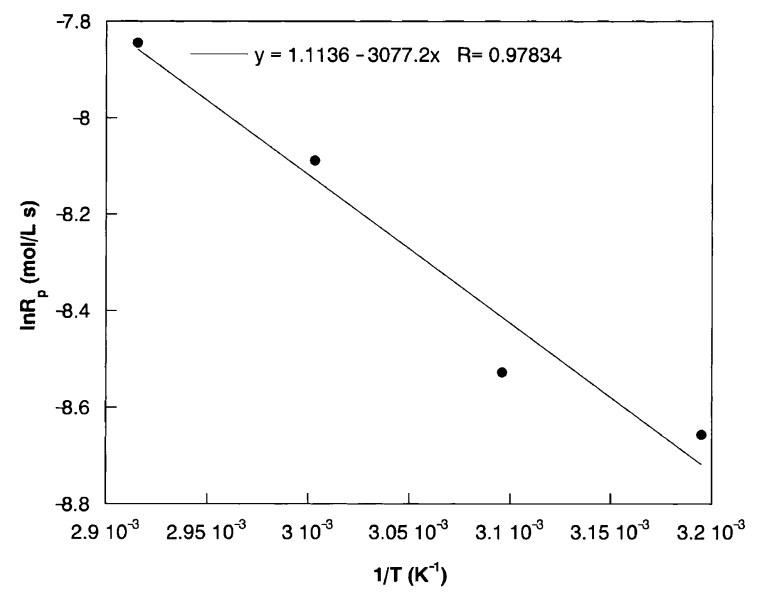

Figure 4. Arrhenius plots of $R_{\mathrm{p}}$ in the polymerization of IPS with SPS in water at different temperatures $\left([\mathrm{IPS}]=1.67 \mathrm{~mol} \mathrm{~L}^{-1}\right.$, $[\mathrm{SPS}]=1.13 \times 10^{-2} \mathrm{~mol} \mathrm{~L}^{-1}$ ).

sodium $p$-styrenesulfonate, and thus the control of $R_{\mathrm{p}}$ is mildly achieved.

$R_{\mathrm{p}}$ was determined in various IPS and SPS concentrations at $50^{\circ} \mathrm{C}$ in a similar manner as above (Table I). Figure 5 presents the effects of IPS concentration on $R_{\mathrm{p}}$ at $50^{\circ} \mathrm{C}$ when the initial concentration was fixed at $1.00 \mathrm{wt} \%\left(1.13 \times 10^{-2} \mathrm{~mol} \mathrm{~L}^{-1}\right) . R_{\mathrm{p}}$ was proportional to the 1.48 power of monomer concentration indicating much higher dependence of $R_{\mathrm{p}}$ on the monomer concentration than the first-order dependence usually observed in radical polymerization. Although the viscosity of the polymerization was not investigated in this paper, we speculated that the higher dependence of $R_{\mathrm{p}}$ on the monomer concentration results in retardation of termination due to the viscosity effect. This causes acceleration of polymerization which has been reported

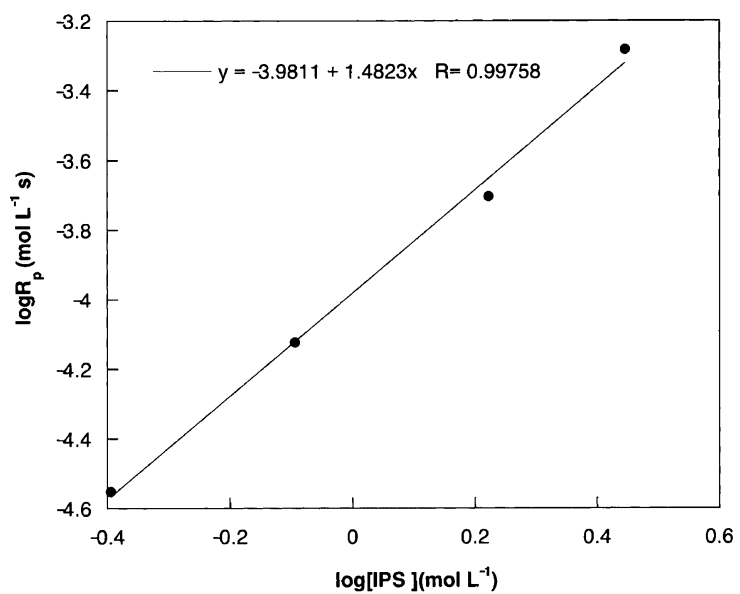

Figure 5. Relationship between polymerization rate $\left(R_{\mathrm{p}}\right)$ and IPS concentration at $50^{\circ} \mathrm{C}$ in water $\left([\mathrm{SPS}]=1.13 \times 10^{-2} \mathrm{~mol} \mathrm{~L}^{-1}\right)$.

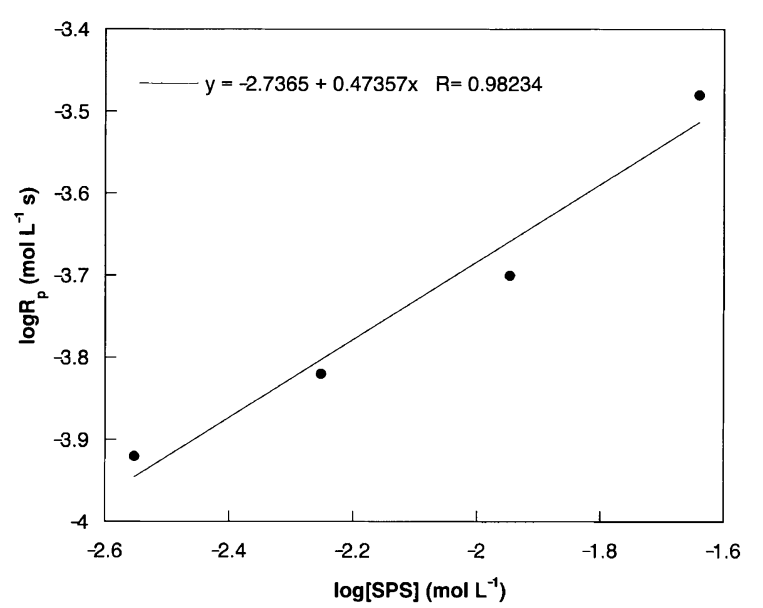

Figure 6. Relationship between polymerization rate $\left(R_{\mathrm{p}}\right)$ and SPS concentration at $50^{\circ} \mathrm{C}$ in water $\left([\mathrm{IPS}]=1.67 \mathrm{~mol} \mathrm{~L}^{-1}\right)$.

in various radical polymerization systems. ${ }^{10-12}$ Figure 6 shows the effects of SPS concentration on $R_{\mathrm{p}}$ at $50^{\circ} \mathrm{C}$ when the initial IPS concentration was fixed at $25.0 \mathrm{wt} \%\left(1.67 \mathrm{~mol} \mathrm{~L}^{-1}\right) . R_{\mathrm{p}}$ increased in proportion to the 0.47 power of the initiator concentration, indicating that the present polymerization involves usual bimolecular termination between propagating polymer radicals. ${ }^{13}$ Detailed studies on solution viscosity, molecular weight, stereochemistry, $\mathrm{pH}$-dependence and copolymerization will be published elsewhere.

\section{SUMMARY}

Polymerization of sodium IPS was kinetically investigated in water using SPS as initiator. The conversion of monomer to homopolymer was determined from decrease in the conjugated diene peak of IPS monomer as measured by UV spectrometry. $E_{\mathrm{a}}$ of polymerization was $25.6 \mathrm{~kJ} \mathrm{~mol}^{-1}$. $R_{\mathrm{p}}$ was expressed by $R_{\mathrm{p}}=$ $k[\mathrm{SPS}]^{0.47}[\mathrm{IPS}]^{1.48}$, indicating that the polymerization of IPS involves usual bimolecular termination between 
propagating polymer radicals, and that deviation from the first-order dependence may possibly be attributed to viscosity. These new kinetic data are considered useful for further investigation.

Acknowledgments. The authors thank JSR Corporation for supplying IPS. The authors thank Drs. Virgil Percec, Ulrica Edlund, Catherine Mitchell, Satoshi Uchida, Yoshiko Miura and Makoto Obata of the University of Pennsylvania and Drs. Tetsuo Mori and Katsuhiro Watanabe of Kurume National College of Technology for valuable advice.

\section{REFERENCES}

1. a) E. A. Bekturov and Z. Kh. Bakauova, Ed., "Synthetic Water-Soluble Polymers in Solution," Hüthig \& Wepf Verlag, Basel, Heidelberg, Germany, 1986. b) Z. Amjad, Ed., "Water Soluble Polymers, Solution Properties and Application", Plenum Publishing Corporation, New York, N.Y., 1998.

2. H. Mark, N. Bikales, C. Overberger, G. Menges, and J. Kroshwitz, Ed., "Encyclopedia of Polymer Science and Engineering”, John Wiley \& Sons Inc., New York, N.Y., 1985, vol. 17, pp 760-763.

3. H. Ono, K. Ito, T. Uekawa, and K. Ishikawa, Japan Patent 2
590790 (Mar. 12, 1997, H9), H. Ono, K. Ito, T. Uekawa, and K. lshikawa, Japan Patent 2809213 (Oct. 8, 1998, H10). H. Ono, K. Ito, T. Uekawa, and K. lshikawa, U. S. Patent 5350 820 (Sep. 27, 1994).

4. H. Ono, Ph D. Thesis, Mie University, Japan, 2000 (English).

5. T. Ogura, M. Tanoura, K. Tatsuhara, and A. Hiraki, Bull. Chem. Soc. Jpn., 67, 936 (1994).

6. A. Oki, S. Fukuda, K. Naka, and S. Maeda, Sekiyu Gakkaishi, 39, 129 (1996).

7. G. Odian, "Principles of Polymerization," 3rd ed, John Wiley \& Sons Inc., New York, N.Y., 1991, pp 208-210.

8. T. F. Mckenna and A. E. Hamielec, 'Activation Energies of Propagation and Termination in Free Radical Polymerization' in "Polymer Handbook", 3rd ed, J. Brandrup and E. Immergat, Ed., John Wiley \& Sons Inc., New York, N.Y., 1989.

9. V. F. Kurenkov, I. A. Kurushkina, E. V. Kuznetsov, and V. A. Kazan, Izv. Vyssh. Uchebn. Zved., Khim. Khim. Tekhnol., 19, 448 (1976)

10. T. Sato, S. Inui, H. Tanaka, T. Ota, M. Kamachi, and K. Tanaka, J. Polym. Sci., Part A: Polym. Chem., 25, 637 (1987).

11. T. Sato, A. Takarada, H. Tanaka, and T. Ota, Makromol. Chem., 192, 2231 (1991).

12. T. Sato, T. Miyoshi, and M. Seno, J. Poym. Sci., Part A: Polym. Chem., 38, 509 (2000).

13. G. Odian, "Principles of Polymerization", 3rd ed, John Wiley \& Sons Inc., New York, N.Y., 1991, pp 216-217. 